\title{
Effects of Naphthenic Acids on Rooting of In Vitro Grown Sequoia sempervirens
}

\author{
A. Halmagyi ${ }^{1}$, S. Kevresan ${ }^{2}$, B. Kovacevic ${ }^{3}$, S. Orlovic ${ }^{3}$, D. Miladinovic ${ }^{4}$, \\ V. Cirin-Novta ${ }^{5}$ and K. Kuhajda ${ }^{5}$ \\ ${ }^{1}$ Institute of Biological Research, 400015 Cluj-Napoca, Republicii str. 48, Romania \\ ${ }^{2}$ Faculty of Agriculture, 21000 Novi Sad, Dositeja Obradovica 8, Serbia \\ ${ }^{3}$ Institute for Lowland Forestry and Environment, 21000 Novi Sad, Antona Cehova 13, \\ Serbia \\ ${ }^{4}$ Institute of Field and Vegetable Crops, Novi Sad, Serbia \\ ${ }^{5}$ Faculty of Science, 21000 Novi Sad, Dositeja Obradovica 3, Serbia
}

Keywords: naphthenates, micropropagation, rooting, shoots

\begin{abstract}
The study describes the effect of naphthenates and their fractions on rooting of in vitro grown Sequoia sempervirens (Lamb. ex D. Don) Endl. shoots. Natural naphthenic acids have been isolated by alkaline extraction from the middle gas fraction of the crude oil. Sequoia sempervirens shoots $(1 \mathrm{~cm}$ in length) were grown on Murashige and Skoog (1962) (MS) medium supplemented with either total naphthenate preparation, naphthenate fractions obtained by extraction on different pH (pH 2, pH 4, pH 7 and pH 9), or indole-3-butyric acid (IBA) in different concentrations (twenty treatments tested). The rooting testing was based on number and total length of roots formed after four weeks of in vitro growth. Similarly to total length of roots, the highest number of roots per explant $(\approx 7)$ was achieved in medium containing $50 \mu \mathrm{M}$ of the naphthenate fraction extracted at $\mathrm{pH} 2$ and in medium containing $50 \mu \mathrm{M}$ of the fraction extracted at $\mathrm{pH}$ 9. That is triple higher than in the control and significantly better than in the best IBA-treatment $(50 \mu \mathrm{M}$ IBA), where five roots per explants in average were formed. Similar to the results obtained for some agricultural and tree forest species, our results with Sequoia sempervirens confirm the possibility of rooting stimulation by naphthenates.
\end{abstract}

\section{INTRODUCTION}

Naphthenic acids represent a complex mixture of cycloalkyl and alkylcarboxylic acids that are found in raw oil, and could contain more than 3000 compounds (Qian and Robbins, 2001; Clemente and Fedorak, 2005). These compounds exhibited a certain biological activity with respect to uptake of various ions (Kevrešan et al., 2005a), as well as an activity similar to auxin (Ćirin-Novta et al., 2002). Naphthenic acids from this oil fraction stimulate rooting of sunflower cuttings (Kevrešan et al., 2003a), poplar hardwood cuttings (Kevrešan et al., 2003b) and softwood cuttings of Thuja occidentalis L. (Kevrešan et al., 2006). Naphthenate treatment influenced the rooting of black locust, Robinia pseudoacacia shoots in vitro (Kevrešan et al., 2005b) and caused biochemical changes in softwood cuttings of Robinia pseudoacacia (Kevrešan et al., 2007).

Sequoia sempervirens (Lamb. ex D. Don) Endl. (called redwood or coast redwood) is a vulnerable species native to the central and northern California coast (IUCN, 2007). It has highly decorative value as introduced species in Europe. However, its limited distribution and the shortage of seeds, as well as its low germination capacity emphasize the necessity of development of vegetative means of propagation, especially micropropagation (Iliev and Trifonov, 1996).

The aim of this work was to investigate the effects of naphthenates, in total preparation and by examined fractions, on rooting of in vitro grown Sequoia sempervirens shoots. 


\section{MATERIAL AND METHODS}

\section{Isolation, Characterization and Fractionation of Naphthenic Acids}

Total naphthenic acids preparation was isolated by alkaline extraction from the middle gas fraction (distillation interval $168-290^{\circ} \mathrm{C}$, obtained from NIS Oil Refinery, Novi Sad) of the crude oil "Velebit" (oil-gas field "Velebit", southeastern part of Pannonian Basin, Autonomous Province of Vojvodina, Republic of Serbia) and characterized by physico-chemical methods, as described earlier by Ćirin-Novta et al. (2002). Preparation of total naphthenic acids was fractionated based on acid ionization constants. The naphthenic acids were dissolved in a $5 \%$ solution of $\mathrm{NaOH}$ at $\mathrm{pH} 11$ and the $\mathrm{pH}$ was subsequently decreased with $\mathrm{H}_{2} \mathrm{SO}_{4}$ and at different $\mathrm{pH}(\mathrm{pH} 2, \mathrm{pH} 4, \mathrm{pH} 7$ and $\mathrm{pH}$ 9); undissolved naphthenic acids were obtained by extraction with petroleum ether. In all experiments the sodium salt of naphthenic acids (sodium naphthenates) were used.

Characterization of total preparation of naphthenic acids showed the presence of five classes of carboxylic acids with different content in total acid mixture (\% mass): aliphatic $\mathrm{C}_{\mathrm{n}} \mathrm{H}_{2 \mathrm{n}} \mathrm{O}_{2}(2 \%)$, monocyclic $\mathrm{C}_{\mathrm{n}} \mathrm{H}_{2 \mathrm{n}-2} \mathrm{O}_{2}(21 \%)$, bicyclic $\mathrm{C}_{\mathrm{n}} \mathrm{H}_{2 \mathrm{n}-4} \mathrm{O}_{2}(42 \%)$, tricyclic $\mathrm{C}_{\mathrm{n}} \mathrm{H}_{2 \mathrm{n}-6} \mathrm{O}_{2}(28 \%)$ and tetracyclic $\mathrm{C}_{\mathrm{n}} \mathrm{H}_{2 \mathrm{n}-8} \mathrm{O}_{2}(6 \%)$. The average molecular mass of naphthenic acids was determined to be 262 , and this value was used to prepare solutions for rooting experiments.

\section{Rooting Experiments}

In vitro-grown Sequoia sempervirens (Lamb. ex D. Don) Endl. plants were selected for rooting experiments. Shoots (1 cm in length) were grown on Murashige and Skoog (1962) (MS) medium supplemented with $1 \mathrm{mg} \mathrm{L}^{-1}$ vitamins, $30 \mathrm{~g} \mathrm{~L}^{-1}$ sucrose and 7 $\mathrm{g} \mathrm{L}^{-1}$ agar (Sigma). The $\mathrm{pH}$ was adjusted to 5.7 before autoclaving. The plants were grown at $24^{\circ} \mathrm{C}$ during a $16 \mathrm{~h}$ light photoperiod with a light intensity of $40 \mathrm{mmol} \mathrm{m} \mathrm{m}^{-2} \mathrm{~s}^{-1}$ photosynthetic active radiation (PAR) provided by cool white fluorescent tubes. The shoots were gained by micropropagation from nodal segments consisting of a piece of stem about $15 \mathrm{~mm}$ in length were transferred to fresh medium and incubated as mentioned above. Subcultures of the plants were performed every four weeks.

Culture medium was supplemented with either total naphthenates preparation, naphthenate fractions obtained by extraction on different $\mathrm{pH}(\mathrm{pH} 2, \mathrm{pH} \mathrm{4,} \mathrm{pH} 7$ and $\mathrm{pH}$ 9), or indole-3-butyric acid (IBA). Twenty treatments were tested. The abbreviations for the treatments consist from three parts. The first part describe whether the active substance is mixture of naphthenic acids or IBA, the second (only for naphthenates) the $\mathrm{pH}$ of extraction or "tot" for total naphthenates preparation, and the third that refers to the concentration. Following treatments were examined: na-tot-10, na-tot-50, na-tot-100 treatments with total naphthenic acids at concentrations 10,50 and $100 \mu \mathrm{M}$, respectively; na-pH2-10, na-pH2-50, na-pH2-100 treatments with fraction of total naphthenic acids obtained at $\mathrm{pH} 2$ at concentrations 10,50 and $100 \mu \mathrm{M}$, respectively; na-pH4-10, na-pH450, na-pH4-100 treatments with fraction of total naphthenic acids obtained at $\mathrm{pH} 4$ at concentrations 10,50 and $100 \mu \mathrm{M}$, respectively; na-pH7-10, na-pH7-50, na-pH7-100 treatments with fraction of total naphthenic acids obtained at $\mathrm{pH} 2$ at concentrations 10 , 50 and $100 \mu \mathrm{M}$, respectively; na-pH9-10, na-pH9-50, na-pH9-100 treatments with fraction of total naphthenic acids obtained at $\mathrm{pH} 9$ at concentrations 10,50 and $100 \mu \mathrm{M}$, respectively; IBA-10, IBA-50, IBA-100, IBA-1g treatments with indole-3-butiric acid at concentrations $10,50,100 \mu \mathrm{M}$ and $4.92 \mathrm{mM}$, respectively. In Control treatment MSmedium without any of examined substances was used. Shoots were placed in jars (one per jar) and six rooted shoots per one treatment were measured. The experiment was repeated twice. The rooting assessment was based on number $(\mathrm{RN})$ and total length (RL $[\mathrm{cm}]$ ) of roots formed after four weeks of in vitro growth. Number of roots was transformed by square transformation $(\sqrt{X})$. Statistical analysis was based on the average value for six jars of the treatment within repetition of the experiment and included ANOVA and LSD-test. Statistical program package STATISTICA 7.1 was used (StatSoft Inc., 2006). 


\section{RESULTS AND DISCUSSION}

Characterization of total preparation of naphthenic acids showed the presence of five classes of carboxylic acids with different content in total acid mixture (\%mass): aliphatic $\mathrm{C}_{\mathrm{n}} \mathrm{H}_{2 \mathrm{n}} \mathrm{O}_{2}(2 \%)$, monocyclic $\mathrm{C}_{\mathrm{n}} \mathrm{H}_{2 \mathrm{n}-2} \mathrm{O}_{2}(21 \%)$, bicyclic $\mathrm{C}_{\mathrm{n}} \mathrm{H}_{2 \mathrm{n}-4} \mathrm{O}_{2}(42 \%)$, tricyclic $\mathrm{C}_{\mathrm{n}} \mathrm{H}_{2 \mathrm{n}-6} \mathrm{O}_{2}(28 \%)$ and tetracyclic $\mathrm{C}_{\mathrm{n}} \mathrm{H}_{2 \mathrm{n}-8} \mathrm{O}_{2}(6 \%)$.

Almost all examined fractions, had significant stimulative effect on rooting of Sequoia sempervirens shoots in vitro (Table 1). The results of analysis of variance indicated very significant differences among treatments for bought examined traits (number of roots (RN) and total length of roots (RL)). The highest number of roots in all cases was obtained in treatments where the concentration of active substances had been $50 \mu \mathrm{M}$. The highest number of roots per explants $(\approx 7$, triple more than in the control), and total length of roots (over $10 \mathrm{~cm}$, almost triple more than in the control) was achieved in medium supplemented $50 \mu \mathrm{M}$ of the fraction extracted at $\mathrm{pH} 2$ (na-pH2-50) and medium supplemented with $50 \mu \mathrm{M}$ of the fraction extracted at $\mathrm{pH} 9$ (na-pH9-50) (Table 1). Also, after bought treatments the examined traits were significantly higher than after the best IBA treatment (IBA-50). Stimulative effect of $50 \mu \mathrm{M}$ for total napthenates preparation was observed by Kevrešan et al. (2003a) and Kevrešan et al. (2005b). Rooting stimulation of examined fractions of total naphtenates preparation (that could be considered as a mixture of numerous compounds, according to Qian and Robbins (2001) and Clemente and Fedorak (2005) suggests the presence of one or more active substances in every examined fraction of the total naphtenates preparation.

Treatments with the highest concentrations $(100 \mu \mathrm{M})$ of total preparation of napthenates and examined fractions usually gave the least stimulative effect on rooting of in vitro Sequoia sempervirens plants. Kevrešan et al. (2003a) observed inhibitory effects of high concentrations of Na-naphthenates on rooting of sunflower green cuttings. Also, the inhibitory and toxic effect of higher concentrations of naphthenic acids is a well known ecological problem (Clemente and Fedorak, 2005).

Several researchers suggested potential of naphthenic acids to influence metabolic processes in plants, especially in the course of the formation and activity of roots system. Severson (1972) concluded that potassium-naphthenates stimulated the glucose uptake by root tips of bean plants, while Kevrešan et al. (2005a) showed that low concentrations of Na-naphthenates influence the uptake of some metal ions by soybean plants. Loh and Severson (1974) found that one-day treatment with potassium naphthenates had a stimulant effect on indolacetic acid oxidase activity, one of the key enzymes associated with the process of initiation and activation of root primordia. Ćirin-Novta et al. (2002) reported auxin-like effects of naphthenates, while Kevrešan et al. (2007) found their simulative rooting potential in Robinia pseudoacacia softwood cuttings, at the base of biochemical indicators of root initiation (activity of IAA-oxidases, peroxidases and amylases and content of glucose).

Considering the effect on the number of formed roots and total length of roots on in vitro grown Sequoia sempervirens, our work confirm the results of previous works on rooting stimulation by naphthenates. More formed roots means higher chances for survival during acclimatization phase and further in the field conditions. Napthenates are relatively easy to obtain, and could be a cheap alternative to widely used auxins like IBA or NAA. It could be interesting for further praxis of micropropagation of Sequoia sempervirens, and should be tested in the propagation of this vulnerable species by softwood cuttings.

\section{CONCLUSION}

Our results confirm the rooting stimulation potential of naphthenates for Sequoia sempervirens, like it was reported previously for some agricultural and forest tree species. The best results we obtained with na-pH2-50 and na-pH9-50 treatments that appeared to be twice or triple better then the control treatment, and gave significantly better results than the best examined IBA treatment (IBA-50). These results suggest high potential for the use of napthenates in rooting of Sequoia sempervirens. 


\section{ACKNOWLEDGEMENTS}

This study was supported by the Ministry of Science of the Republic of Serbia, project No. 142005B.

\section{Literature Cited}

Clemente, J.S. and Fedorak, P.M. 2005. A review of the occurrence, analyses, toxicity and biodegradation of naphthenic acids. Chemosphere 60:585-600.

Ćirin-Novta, V., Kuhajda, K.N., Kevrešan, S.E., Kandrač, J.E. and Radić, Lj.M. 2002. Biological activity and structure of natural petroleum acids from lower oil fractions of "Velebit"oil. Acta Periodica Technologica 33:134-137.

Iliev, I. and Trifonov, T. 1996. Influence of donor plant age upon in vitro cloning of Sequoia sempervirens Endl. Forest Science (Sofia) 2:3-11.

Kevrešan, S., Cirin-Novta, V., Vasić, D., Kuhajda, K., Kandrač, J., Petrović, N. and Radić, Lj. 2003a. Effect of naphthenic acids on formation of adventitious roots in sunflower cuttings. Helia 26:18-22.

Kevrešan, S., Ćirin-Novta, V., Kovačević, B., Kuhajda, K., Kandrač, J., Petrović, N. and Radić, $\mathrm{Lj}$. 2003b. Effect of naphthenic acids on root formation in the hardwood cuttings of clones of section Leuce and Aigeiros. Topola 171/172:63-72.

Kevrešan, S., Ćirin-Novta, V., Kuhajda, K., Kandrač, J., Petrović, N., Grbović, Lj. and Kevrešan, Ž. 2005a. Effect of low concentration of sodium naphthenate on uptake of some metal ions by soybean plants. Belgian Journal of Botany 138:11-13.

Kevrešan, S., Kovačević, B., Vasić, D., Cirin-Novta, V. and Kuhajda, K. 2005b. The influence of Na-naphthenates and kinetin on rooting of pyramidal black locust genotype shoots in vitro. - Cercetari stiintifice- Horticultura, Seria A IX-A, Partea a II$\mathrm{a}: 1-10$.

Kevrešan, S., Kovačević, B., Ćirin-Novta, V., Kuhajda, K., Katanić, M. and Vasić, V. 2006. The effect of naphthenic acids on rooting of softwood cuttings in Thuja occidentalis L. Proceedings, XXXVI ESNA Annual Meeting, Iasi, Romania. p.527532.

Kevrešan, S., Kovačević, B., Ćirin-Novta, V., Kuhajda, K., Kandrač, J., Pavlović, K. and Grbović, Lj. 2007. Biochemical changes in cuttings of Robinia pseudoacacia after treatment with naphthenate. Journal of the Serbian Chemical Society 72:953-959.

Loh, J.W.C. and Severson, J.G. 1975. Stimulation of indoleacetic acid oxidase of bean plants by naphthenates. Phytochemistry 14:1265-1267.

Murashige, T. and Skoog, F. 1962. A revised medium for rapid growth and bioassay with tobacco tissue cultures. Physiologia Plantarum 15:473-497.

Qian, K. and Robbins, W.K. 2001. Resolution and Identification of Elemental Compositions for More than 3000 Crude Acids in Heavy Petroleum by Negative-Ion Microelectrospray High-Field Fourier Transform Ion Cyclotron Resonance Mass Spectrometry. Energy \& Fuels 15:1505-1511.

Severson, J.G. 1972. Stimulation of ${ }^{14} \mathrm{C}$ - glucose uptake and metabolism in bean root tips by naphthenates. Phytochemistry 11:71-76.

StatSoft Inc. 2006. STATISTICA (data analysis software system), version 7.1.

IUCN. 2007. IUCN Red List of Threatened Species.

Wort, J.D. 1976. Mechanism of Plant Growth Stimulation by Naphthenic Acid. Plant Physiology 58:82-86. 


\section{$\underline{\text { Tables }}$}

Table 1. Number of roots and total length of roots per microshoot of Sequoia sempervirens (Lamb. ex D. Don) Endl. four weeks after the examined treatment.

\begin{tabular}{|c|c|c|c|c|c|}
\hline \multicolumn{3}{|c|}{ Number of roots (RN) } & \multicolumn{3}{|c|}{ Total length of roots $(\mathrm{RL}[\mathrm{cm}])$} \\
\hline Treatments $^{*}$ & LSD- & & Treatments & LSD-t & \\
\hline na-pH2-50 & 7,64 & $\mathrm{a}$ & na-pH2-50 & 12,08 & $\mathrm{a}$ \\
\hline na-pH9-50 & 6,78 & $a b$ & na-pH9-50 & 10,25 & $\mathrm{~b}$ \\
\hline na-pH2-10 & 5,78 & $\mathrm{bc}$ & na-pH2-10 & 9,58 & $\mathrm{~b}$ \\
\hline IBA-50 & 5,18 & $\mathrm{c}$ & na-tot-50 & 8,00 & $\mathrm{c}$ \\
\hline na-pH7-50 & 5,13 & $\mathrm{c}$ & na-pH4-50 & 7,92 & c \\
\hline na-pH7-10 & 4,73 & $\mathrm{~cd}$ & na-pH7-50 & 7,25 & $\mathrm{~cd}$ \\
\hline na-pH2-100 & 4,64 & cde & IBA-50 & 7,17 & cde \\
\hline na-pH4-50 & 4,60 & cdef & na-pH4-10 & 7,00 & cdef \\
\hline na-pH9-10 & 3,84 & defg & na-pH2-100 & 6,75 & cdefg \\
\hline IBA-100 & 3,66 & defg & na-pH4-100 & 6,08 & defgh \\
\hline na-tot-50 & 3,59 & defg & na-pH7-10 & 5,83 & efgh \\
\hline na-pH4-10 & 3,59 & defg & na-tot-10 & 5,75 & fgh \\
\hline na-pH7-100 & 3,50 & efg & na-tot- 100 & 5,75 & fgh \\
\hline na-pH9-100 & 3,46 & $\mathrm{fg}$ & IBA-100 & 5,50 & gh \\
\hline na-tot-10 & 3,12 & $\mathrm{gh}$ & na-pH7-100 & 5,00 & hi \\
\hline IBA-10 & 2,93 & ghi & IBA-10 & 5,00 & hi \\
\hline na-pH4-100 & 2,25 & hij & IBA-1g & 5,00 & hi \\
\hline na-tot-100 & 2,08 & ijk & na-pH9-100 & 4,92 & hi \\
\hline Control & 2,01 & $\mathrm{jk}$ & na-pH9-10 & 4,08 & $\mathrm{i}$ \\
\hline IBA-1g & 1,36 & $\mathrm{k}$ & Control & 3,83 & $\mathrm{i}$ \\
\hline
\end{tabular}

${ }^{*}$ Labels of treatments: na-tot-10, na-tot-50, na-tot-100 treatments with total naphthenates preparation at concentrations 10, 50 and $100 \mu \mathrm{M}$, respectively; na-pH2-10, na-pH2-50, na-pH2-100 treatments with fraction of total naphthenats obtained at $\mathrm{pH} 2$ at concentrations 10, 50 and $100 \mu \mathrm{M}$, respectively; na-pH410, na-pH4-50, na-pH4-100 treatments with fraction of total naphthenats obtained at $\mathrm{pH} 4$ at concentrations 10, 50 and $100 \mu \mathrm{M}$, respectively; na-pH7-10, na-pH7-50, na-pH7-100 treatments with fraction of total naphthenats obtained at $\mathrm{pH} 2$ at concentrations 10,50 and $100 \mu \mathrm{M}$, respectively; na-pH910, na-pH9-50, na-pH9-100 treatments with fraction of total naphthenats obtained at $\mathrm{pH} 9$ at concentrations 10, 50 and $100 \mu \mathrm{M}$, respectively; IBA-10, IBA-50, IBA-100, IBA-1g treatments with indole-3-butiric acid at concentrations $10,50,100 \mu \mathrm{M}$ and $4.92 \mathrm{mM}$ respectively; Control- treatment without examined active substances. 
